ARID International Journal of Social Sciences and Humanities (AIJSSH) VOL.3, NO.5, January 2021

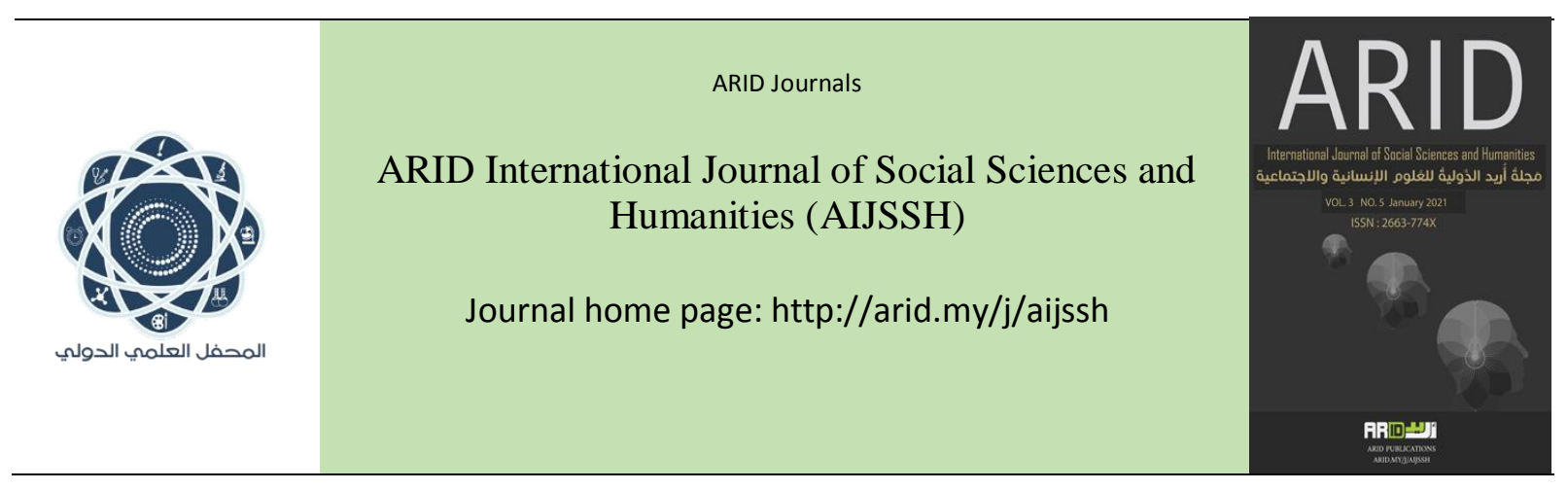

$$
\begin{aligned}
& \text { مَجلةُ أُريد الدَّوليةُ للعُلورج الإنسانية والإجتماعية } \\
& \text { البحلد الثالث ،العدد الخامس، كانون الثاني } 2021 \text { م }
\end{aligned}
$$

\title{
The impact of family and society on the motivation of learning among students in high school
}

\author{
Anas AlSalhy \\ أثر الأسرة والمدرسة على دافعية التعلم لاى الطلبة في المدراس الثانوية \\ انس يحيى إسماعيل الصالحي \\ ديوان الوقف السني ـدائرة التعليم الديني و الدراسات الإسلامية ـالعراقـ- بغداد
}

\section{Anas2001320013@gmail.com}

Arid.my/0001-8161

https://doi.org/10.36772/arid.aijssh.2021.357 




\begin{abstract}
The research aims to show the effect of the family and the school on the motivation of learning among students in secondary schools, and which of them has a greater impact on the motivation of learning for students of the family or school or both. So the problem here is that the role of the family and the school has an impact on the educational process and the educational level of the student as for the questions that have been The answer to it through the investigation is what is the role of the family in the motivation of learning among students and what is the role of the school in this motivation or whether the two together have an important role for the motivation of learning and what is the role of the family in raising the motivation of learning and what is the role of the school, and the descriptive method has been used to describe the three cases And results were found that show that the role of the family is the most important role among the axes, because the family is the primary axis in the formation of the individual from childhood until crossing the adolescence role upwards. Very much in raising the motivation of students in learning and the presence of social and psychological counselors in schools has a big role in solving students 'problems in schools and that the role of media and broadcasting organizations has a large role in the learning process as well as the process of rewards used by parents or teachers have a major role in pushing students to Learning.
\end{abstract}

Keywords: motivation of learning, family, schools, secondary schools, 


\section{الملخص}

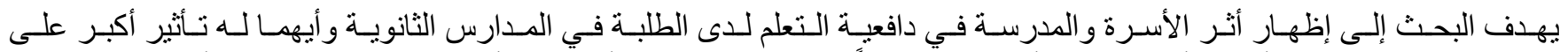



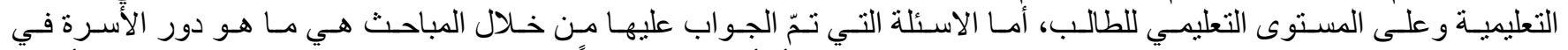

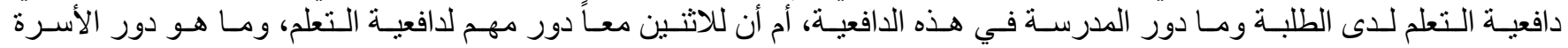

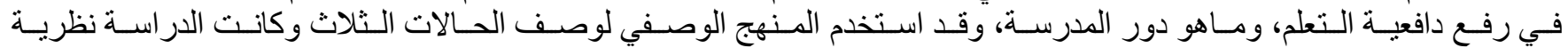

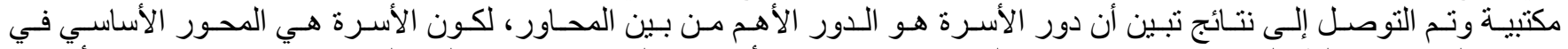

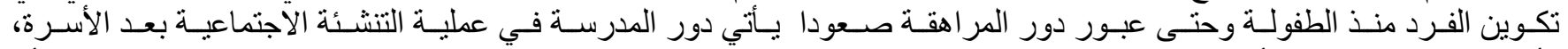

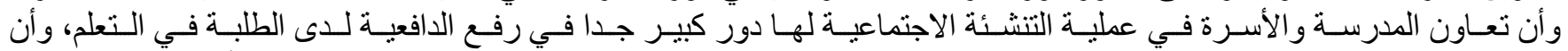

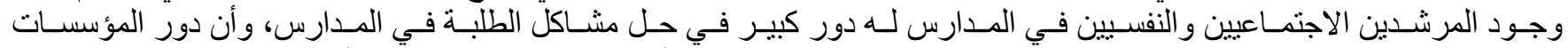

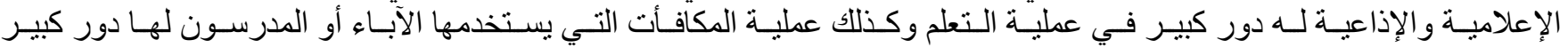
في دفع الطلاب إلى التعلم.

الكلمات المفتاحية: دافعية التعلم، الأسرة، المدرسة، طلبة الثانويات، المؤسسات التربوية. 
تعتبر الأسرة المؤسسة الاجتماعية الأولى المسئولة عن التنشئة الاجتماعية والضبط الاجتماعي، فالأسرة اتحاد تلقائي يتم نتيجة القدرات الكامنة في الطبيعة البشرية التي تشجع على الاجتماع وهي ضرورة حتمية لبقاء الجنس البشري وبقاء الوجود الاجتماعي. وتلعب الأسرة دور أساسيا في سلوك الأفراد بطريقة جيدة أو غير جيدة من خلال التوجيهات السلوكية التي تقدمها لأبنائها، فأنماط السلوك والتفاعلات التي تدور داخل الأسرة هي النماذج التي تؤثر سلبا أو إيجابا في نربية الأبناء، على الرغم من وجود مؤسسات اجتماعية تقدم التربية و التوجيه للأبناء إلا إن الأسرة كانت ولا زالت أقوى مؤسسة اجتماعية تؤثر في كل توجهات الإنسان المادية و المعنوي، فالأسرة هي المؤسسة الأولى في حياة الإنسان وهي مؤسسة مستمرة معه استمر ار حياته بصورة مباشرة أو غير مباشرة إلى إن يشكل أسرة جديدة خاصة به. بالإضافة إلى ذلك فالأسرة هي المؤسسة التي ترعى الطفل وتحميه وتشبع حاجاته وتلبي رغباته، إضافة إلى ذلك هي التي تساعده على الانتقال من حالته البيولوجية إلى حالته الاجتماعية ليصبح قادر ا على الاعتماد على نفسه في شؤونه الخاصة و العامة وقادر ا على التو افق مع مطالب المجتمع وقيمه. [1] إضافة إلى دور الأسرة فاللمدرسة دور مهم أيضا في دافعية التعلم لدى الطلاب، لأن المدرسة مؤسسة اجتماعية أوجدها المجتمع لتحقيق أهدافه وغايته، وهي مؤسسة تربوية نظامية مسئولة عن توفير بيئة نربوية تهدف إلى تنمية شخصية الطالب للعلم من جميع جوانبها الجسمية و العقلية و النفسية والأخلاقية والاجنماعية.

ونظر اللظروف الاقتصادية الصعبة التي يمر بها البلد مما اضطر بالمر أة الخروج إلى العمل، حيث بدأت الأسرة تفقد بعضا من وظائفها الاجتماعية لصالح تللك المؤسسات الاجتماعية التربوية وهي المدارس والمعاهد والكليات، وما كانت تقوم به الأسرة أصبح منقسما بين الأسرة والمدرسة وخاصة في مساعدتهم على مو اجهة ظروف الحياة وما يوجد فيها من أفكار سلبية و إيجابية ودور المدرسة على توجيه الطلبة إلى الأفكار الايجابية والابتعاد عن الأفكار السلبية في جميع مجالات الحياة، لذلك تعد المدرسة الحلقة الأولى في التعليم النظامي المقصود وحلقة مكمّلة للتربية الأسرية وحلقة وصل مهمة بين البيت والمجتمع، فالمدرسة تسمح بالإشر اف المستمر على طول مرحلة الطفولة والمر اهقة من خلال عملية تربوية يمارسها تربويون متخصصون لهم خبر اتهم ومعارفهم بطبيعة التلميذ، وما يحتاجه من بيئة مناسبة وأدوات ومعلومات تستثير نشاطه في الرغبة إلى العلم والعم . 
اولاً : مشكلة البحث: تتحدد المشكلة في السؤال التالي: ما دور الأسرة والمدرسة في العملية التعليمية وأثر ها على المستوى التعليمي للطالب؟ ثانياً : فرضية البحث: تأتي الفرضية في جانبين هما: 1- يلعب الخطاب الأسري للو الدين حول المدرسة دور مهماً في النجاح المدرسي للطلاب ويأتي في ثلاثة محاور: أــ الخطاب الأسري للو الدين الذي يشجعهم ويحفز هم على النجاح. بـ الخطاب الأسري للو الدين الذي يبين لهم الجانب الإيجابي اتجاه المدرسة و المدرسين ليساعدهم في النجاح و التفوق. ج- الخطاب الأسري للو الدين للاهتمام بالمدرسة ويودي بالطالب إلى النجاح في المدرسة. 2- يأتي دور المدرسة مكملاً لدور الأسرة والتو اصل الدائم بين المدرسة والأسرة للوصول إلى نتائج جيدة في عملية التعليج. ثالثاً : أسئلة البحث: يجيب الإجابة عن الاسئلة التالية: 1- هل دور الأسرة مهم في رفع دافعية التعلم لدى الطلبة في المدارس ؟ 2- هل دور المدرسة مهم في رفع دافعية التعلم لدى الطلبة في المدارس؟ 3- هل دور الأسرة والمدرسة معاً مهم في رفع دافعية التعلم لدى الطلبة في المدارس؟ 4- أيهما أهم دور الأسرة أم المدرسة في رفع دافعية التعلم لدى الطلبة؟ رابعاً : أهمية البحث : تتحدد الأهمية في المحاور التالية: 1- التعرف على دور الأسرة والمدرسة في العملية التعليمية للطالب. 2- تستفيد منه وزارة التربية ودائرة التعليم الدين، و الدرسات الإسلامية لرفع مستوى التعليم في مدارسها. خامساً : أهداف البحث: الهدف الرئيسي هو التعرف على دورالأسرة والمدرسة في العملية التعليمية للطلاب وأيهما له الدور الأفضل. سادساً: منهج البحث: يستخدم الباحث المنهج الوصفي لكونه الأنسب هنا من خلال جمع البيانات و المعلومات وتقديم وصف لها. 


\section{المبحث الأول: الأسرة}

توجد في هذا الموضوع العديد من الدراسات السابقة وفي سنوات مختلفة نعرض واحدة منها وهي واقع التكامل الوظيفي بين الأسرة و المدرسة وتأثيره على التحصيل الدراسي للتلميذ وهي رسالة ماجستير نوقتت في جامعة الوادي كلية العلوم الاجتماعية والانسانية الجزائر 2014 ونحن سوف نبحث في مفهوم الأسرة والتكوين الاجتماعي لها، وكذللك المدرسة ودور كلُ منهم في عملية التعلم لدى الطلبة وفي هذا المبحث سنتناول كل ما يخص الأسرة ونبدأ بتعريفاتها:

أـالتعريف اللغوي للأسرة:الأسرة من الناحية اللغوية كما ورد في لسان العرب تعني عشيرة الرجل و أهل بيته ور هطه الأدنون لأنه يتقوى

ب-التعريف الاصطلاحي :ليس لاصطلاح الأسرة تعريف ومعنى واضح يتفق عليه العلماء بالرغم من كونها أحد أهم الوحدات الأساسية التي يتكون منها البناء الاجتماعي حيث إن تعريفها يختلف من عالم إلى آخر:

حيث عرفها أوجست كونت: بأنها الخلية الأولى في جسم المجتمع، وهي النقطة الأولى التي يبدأ منها التطور، وهي الوسط الطبيعي الاجتماعي الذي يترعرع فيه الفرد.

أما أحمد زكي بدوي يعرف الأسرة في معجم مصطلحات العلوم الاجتماعية على أنها الوحدة الاجتماعية التي تهدف إلى المحافظة على

النوع الإنساني وتقوم على المقتضيات التي يرتضيها العقل الجمعي والقو اعد التي تقر ها المجتمعات المختلفة. [3] و هنالك تعاريف كثيرة للأسرة من مختلف علماء العرب منهم وغير العرب و عليه يمكن تعريف الأسرة على أنها" أهم جماعة أولية في المجتمع وتتكون من عدد من الأفراد تتأسس بينهم القرابة بناء على محور الانتساب حيث ترتبط بروابط الزواج أو الدم يقيمون في منزل واحد. [3 ] أما التكوين الاجتماعي للأسرة فيمكن تحديد الوحدات المكوّنة للأسرة كما يلي: _الوالدان :الأب والأم :( يعتبر الأب والأم مركز العطاء في الأسرة وتوجيه نمط التنشئة الاجتماعية وتمويلها ماديا ومعنويا. _الابناء : المكون الثاني للأسرة هم الأبناء من الجنسين وتتخخل ثقافة الأسرة ومستواها الاقتصادي في إنجاب الأطفال، فميل الأسر ذات الثقافة العالية إلى إنجاب عدد قليل من الأطفال، في حين تميل الأسر ذات المستوى الاقتصادي المنخفض إلى إنجاب عدد كبير من الأطفال، وعدم المبالاة بصعوبة الحياة و عسر المعيشة وممكن يرجع ذللك أيضا إلى قلة الثقافة لدى تلك العائلات، و الو اقع أن تربية الأبناء ليس بالأمر السهل بل هي مسؤولية كبيرة تقع على عاتق الأسر، حيث يتطلب الأمر الكثير من الجهد والتخطيط، فإذا ابتغى الوالدان

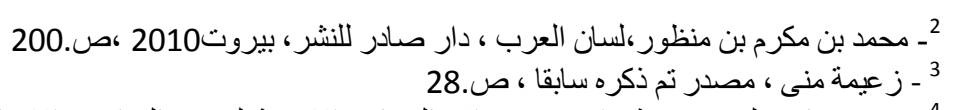

4- عمرونيتارزوليت حورية واخرون ، واقع المساندة الاسرية لبعض المدارس الابتدائية في ولاية الو ادي ، جامعة قاصدي ، الموتمر العلمي الثاني، الجزائر 
التوفيق في تربية أبناء صالحين وبناء مستقبل واعد لهم ينبغي عليهما تحديد أهداف تربوية معينه ومعرفة الوسائل والطرق اللازمة للحصول على تللك الأهداف حيث يشكل ذلك برنامجا تربويا متكاملا. [5] _الجد والجدة: نجد الجد والجدة لهما دور فعال في إدارة الأسرة وتمثيلها في المراسم الاجتماعية كالزواج، ونرى هذا الدور في مجتمعنا نحن العراقيين لأننا من ذوي الأسر المتدة التي تبقى مرتبطة بنوجيهات الأب والأم والجد والجدة بخلاف الأسر النووية التي تنتشر فيها ظاهرة الاستقلال الكلي عند وصول الابن لمرحلة الزواج ـ [ ] نلخص مما سبق أن الأسرة الممتدة يغيب فيها مبدأ الاستقلالية واتخاذ القرار ويكثر فيها الإهمال بسبب كثرة الأطفال وعدم إمكانية الآباء إعطاء الأبناء حقهم من الاهتمام والرعاية، في حين نجد الأسرة النووية ذات استقلالية أكبر من الأسرة المتندة من حيث إعطاء الحرية للأو لاد حيث تقوم بتلبية كل احتياجاتهم المادية والاجتماعية و النفسية وتوفر الحب والرعاية الكافية إضافة إلى كونها لا تنقطع عن الجد و الجدة وتبقى منو اصلة معهم.][

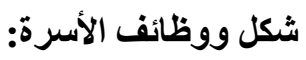

تختلف أثكال الأسر في مجتمعنا عبر التاريخ لذلك يجب عند ذكر الأسرة نحديد نوعها ويتفق علماء الاجتماع على وجود نوعين من الأسرة في المجتمعات العربية بصورة عامة و المجتمع العر اقي بصورة خاصة هما الأسرة الممتدة والأسرة النواة، أما الأسرة الممتدة فهي التي تثمل عدة أجيال في آن واحد، كأن تثمل الأسرة على الجد والجدة والأبناء وزوجاتهم والأحفاد، ومن بين ما عرفت به أيضا أنها تتكون ليس من الآباء و الأبناء، وإنما تمند لتنشمل الأقارب الآخرين، الأجداد والأعمام والعمات و أطفالهم الكتزوجين وزوجاتهم وأطفالهم غير الكتزوجي، يثكلون حياة اقتصادية اجتماعية واحدة تحت رئاسة الأب أو رئيس الأسرة . [ [ أما الأسرة النواة فيطلق عليها الأسرة الزوجية او الزواجية أو الأسرة البسيطة وهي أصغر وحدة في المجتمع تتكون من الأب والأم والأو لاد يسكنون في بيت واحد ويكون بين أفر ادها التزامات متبادلة اقتصادية واجتماعية و هناك من يعرفها بأنها جماعة صغيرة تتكون [?] [من زوج وزوجة و أبناء غير بالغين تقوم كوحدة مستقله عن باقي المجتمع وتتسم هذه النوعية من العائلات بصلابة العلاقات الاجتماعية بين الزوجين خصوصا عندما يكون الأطفال صغار ولكن سرعان ما تضعف هذه العلاقة بعد بلوغ ونضج الأطفال، وقد تقطع علاقات البناء بالآباء بعد الزواج، ويرجع السبب في صلابة العلاقات في الأسرة النواة لأنها تعتمد على الجذب الجنسي بين الزوجين والصداقة ووجود الأهداف المشتركة بين الآباء والأبناء.



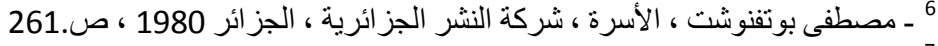



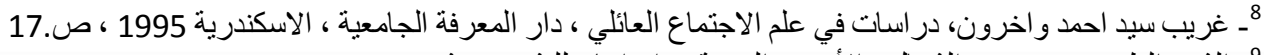


أما بالنسبة لوظائف الأسرة حيث يقع على عاتقها الكثير من الوظائف التي تكون ملزمة في توفير ها للأبناء منها: أولاً :الوظيفة النفسية

: التي تتمثل في إثباع الحاجات النفسية المتمثلة في الأمن والاستقر ار و الثقة بالنفس هذا من خلال الوحدة الأسرية وتماسكها التي تلعب دورا بارزا في نمو الذات للطفل والفرد، التي تتمثل فيما يقدمه الأب و الأم للأبناء من مشورة ونصائح تم اكتسابها من خبر اتهم في الحياة على مرور العمر مما يؤدي إلى بناء الثقة في نفس الابن وشعوره بالاطمئنان والابتعاد عن التعنيف والضرب للأطفال والاكتفاء بالنصيحة وتصحيح المسار. على العكس منها الاستخدام السيئ للعلاقات النفسية المنبادلة وغياب الإشاعات النفسية يؤدي إلى خلخلة الجو الأسري مما يختل النضج النفسي للابن، حيث تؤكد التربية الحديثة على تفعيل حواس الفرد ودفعه إلى فهم حسن الأشياء أو قبحها ويو اجه بذاته شتى الأمور ولذتها بمساندة الأب و الأم في تقدم المشورة، مما يدفع بالفرد للاخول إلى معترك الحياة الاجتماعية والفكرية ليكتسب المهارة بالحياة الفردية و الجماعية ليكون قادر ا على الكسب و العمل فردا ينفع المجتمع لا عالة عليه. [10]

ثانياً :الوظيفة الاجتماعية:

حيث تقوم الأسرة بتعليم الفرد لغة الجماعة التي ينتمي إليها وعاداتها وتقاليدها و آدابها وتعمل على تدريبه على كيفية التعامل مع أفراد المجتمع الآخرين التي تسمح له بممارسة حياة اجتماعية ودور اجتماعي، يتناغم ويتناسب مع قيم مجتمعه ويتفق مع البيئة التي يعيش فيها، وبالتالي تسمح له المكانة الاجتماعية التي تنتقل من الأسرة إلى الأفر اد، فالأسرة تمارس وظيفة الاندماج في المجتمع بحيث تقوم بوضع الفرد في مر اكز هم المختلفة التي تعود على المتمع والبلد التي يعيش فيه الفرد بالمنفعة مؤسسة نظام اجتماعي لا يمكن لأحد تجاوزه.

ثالثاً :الوظيفة الاقتصادية :

تعتبر الأسرة المتمثلة (الأب والأم) الداعم الأول الاقتصادية في توفير الأموال وكل ما يحتاجه الفرد من دعم مادي في حياته الأولية المتمنلة بالتعليم مما يؤدي إلى تعزيز الثقة للفرد في المجتمع وعدم انجر افه إلى طرق ملتوية بسبب العوز المادي أو التقصير من قبل الأسرة تجاه الفرد في المجتمع، وكذلك للأسرة قدرة على خلق فرد منتج كفوء قادر على رفع مستوى الانتاج في المجتمع و البلد و إيصال البلد إلى مرحلة الاكتفاء الذاتي وذلك عن طريق تعليمه وتدريبه على أساليب الاتتاج ورفع مستوى المنفعة إلى أقصى غاية، من خلال 
رفع مسنوى الإبداع لدى الفرد من خلال استثمار أوقات الفر اغوزجه في مجالات تلاحظ الأسرة فيه ميول الفرد لتلاك الاعمال مما يجعله يبدع فيه ويساهم في تقدم ورقي البلد و المجتمع، وبذلك تكون الأسرة قد أعدت فر ادا ناجحا ينتفع منه المجتمع والبلد على حد سواء. [2]

\section{رابعاً :الوظيفة الثقافية :}

تقوم الأسرة بعطلية التنشئة الاجتماعية لدمج الفرد في الإطار الثقافي العام للمجتمع وذلك عن طريق إذخال التراث الثقافي في تكوينه وتوريثه له توريثا متعمد؛ لأن الفرد يكتسب من الأسرة لغته و عاداته وتقاليده وعقيدته حيث ينشأ منذ طفولته في جو مليء بهذه الافكار و المعتقدات و القيم، فتدخل في نفسه وتصبح من مكونات شخصيته فلا يستطيع التخلص منها، حيث يكون لهذا الرصيد من القيم الاجتماعية أثر في حياة الفرد حاضر ا ومستقبلا، حيث ينتقل من مرحلة إلى مرحلة أخرى في حياته حاملا معه تلك العادات و التقاليد ومطبقها في مجتمعه الذي يعيش فيه مع الآخرين لذلك تجد الفرد يعكس ما تعلّمه من و الده ووالدته عبر السنين التي مضت متأثر ا بها لا يستطيع [ تجاوز ها عبر السنين .

\section{أهمية الأسرة في التتشئة الاجتماعية للطالب:}

يجمع الباحثون في مختلف الميادين على أهمية الدور الذي تلعبه الأسرة في حياة الناشئة و الأطفال وهم بذلك ينطلقون من الأهمية الخاصة لمرحلة الطفولة على المستوى البيولوجي و النفسي والاجتماعي، وتؤثر الأسرة على بناء شخصية الطفل بفضل عاملين أساسيين هما ـ النمو الكبير الذي يحققه الطفل خلال سنواته الأولى جسدياً ونفسياً، ثم قضاء الطفل لمعظم وقته خلال سنواته الأولى في عملية التعليم

ــ التنشئة كعطية مستمرة لا تقتصر فقط على مرحلة عمرية محددة وإنما تمتد من الطفولة، فالمراهقة، فالرشد وصولا إلى الشيخوخة ولهذا فهي عملية حساسة لا يمكن تجاوز ها في أي مرحلة لأن لكل مرحلة تنشئة خاصة تختلف في مضمونها وجو هر ها عن سابقتها، ولا يكاد يخلوا أي نظام اجتماعي صغير ا كان أم كبير ا و أي مؤسسة رسمية أو غير رسمية من هذه العملية ولكنها تختلف من و احدة إلى أخرى بأسلوبها لا بهدفها ومن أبرز مؤسسات التنشئة الاجتماعية نجد الأسرة، التي تعتبر البيئة الاجتماعية الأولى التي ينشأ فيها الفرد وتبنى فيها الشخصية الاجتماعية باعتبار ها المجال الحيوي الأمثل للتنشئة الاجتماعية والقاعدة الأساسية في إشباع مختلف حاجات الفرد المادية منها والمعنوية بطريقة تساير فيها المعاير الاجتماعية والقيم الدينية والأخلاقية وذلك من خلال إتباع الوالدين مجموعة من الأساليب في إثباع حاجات الأبناء وخصوصا في فترة المر اهقة ومن هذه الاساليب:

13

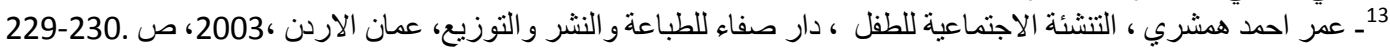
${ }^{14}$ http://montada.echoroukonline.com/showthread.php?t=229623. - - 
- تتمية روح الاخوة والتر ابط المجتمعي مما يؤدي إلى تماسك المجتمع وتر ابطه . - وجود البيئة الأسرية السليمة و العمل الجماعي ونبذ الفردية. - - مجود القدوة الإيجابية وتوفر ها في الأسرة. [15] من خلال الأساليب السابقة يتضح لنا هناك قيم إيجابية نسعى الأسرة العر اقية إلى غرسها في نفوس الأبناء من خلال بث روح التسامح و الابتعاد عن المو اقف المتطرفة وتنمية الشعور بالوحدة الوطنية بين مختلف الطوائف، وكذلك تنمية الاتصال بين أفراد الأسرة وعدم استعمال ألفاظ توحي بالتميز العرقي أو الطائفي وخاصة من قبل قدوة الأسرة المتمنلة بالأب والأم وعدم السماح للاطفال بمشاهدة البرامج و المسلسلات التي تثير العنف والأنانية وكذلك اعتماد مبادئ الدين الإسلامي الحنيف في التعامل مع الآخرين وتعليم الأو لاد مبدأ الاعتذار عندما يخطئون بحق زملائهم؛ لأن الاعتذار عن الخطأ ثقافة الدين الإسلامي الحنيف. [16] إذن التشئة الاجتماعية نشمل كافة الأساليب التي يتلقاها الفرد من الأسرة خاصة الو الدين والمحيطين به من أجل بناء شخصية نامية متو افقة جسميا ونفسيا واجتماعيا وذلك في مو اقف كثيرة منها اللعب والغذاء والتعاون و التتافس و الصر اع مع الآخرين في كافة مواقف الحيا ، لذلك تعتبر التنشئة الاجتماعية من أهم الحاجات التي تقع على عاتق الأسرة والإخفاق فيها يعني الإخفاق في إنشاء جيل واعي يؤثر سلبا على المجتمع خاصة و على البلد و على البلد بصورة عامة. [17 العوامل المؤثرة في الدور التربوي للأسرة: هناك عدة عو امل تؤثر على عملية توجيه الفرد داخل الأسرة أهم تللك العو امل: ـ اتجاهات الوالدين: ونقصد باتجاهات الو الدين الطريقة التي يتعامل بها الأب والأم مع الأبناء في عملية التربية أي هو الأسلوب الذي يستخدمه الأبوين في نقل القيم و العادات والمفاهيم الاجتماعية إزاء قضايا معينة وهو ما ير اه الأبوين ويتمسكان به من أساليب معاملة أو لادهم في المو اقف التي تمر بهم، وهو الذي يؤدي بالطفل بالاعتماد على النفس ومساعدته على النمو الاجتماعي. [ ـ البيئة المنزلية : إن للبيئة المنزلية أثر كبير في تنشئة الفرد من خلال ما تتضمنه من علاقات اجتماعية داخل الأسرة و السمات العاطفية التي تطبع على هذه العلاقة من دفه أو برودة لها تأثثر كبير على شخصية الفرد حيث اثتت العديد من الدراسات على أهية البيئة 15ـ فاطمة اسماعيل محمود ، دور الأسرة العر اقية في تتمية بعض القيم الايجابية لدى الأبناء في ظل الظروف الر اهنه ، مجلة كلية الاداب العدد100 ، جامعة ديالى ،

17- http://www.ibtesamah.com/showthread-t 288486.html.

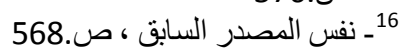


المنزلية في تطبيع الطفل على مرور مر احل نموه، ولكن تتعرض هذه البيئة إلى العديد من المشاكل الاجتماعية منها كضيق المسكن وكثرة عدد الأفر اد والغلاء المعيشي هذا الوضع يجعل القلق يؤثر على الو الدين مما يؤثر سلبا على أسلوبهما في التعامل مع أفر اد الأسرة حيث يضيق الخناق على الأو لاد مما يؤدي إلى التأثير على نمو هم الطبيعي وتحد من استقلاليتهم. [19] ـ ثقافة الوالدين ت تلعب ثقافة الو الدين دور ا مهما في تنشئة الأولاد فيجب أن يكون لديهم إلمام بمبادئ التربية الأساسية التي تتعلق بطبيعة المخلوق الذي هم بصدد رعايته كي تسهل عليهم مهمة تنشئته تنشئه اجتماعية جيدة، لذلك نرى فرق واسع بين تنشئة الفرد في ظل أسرة مثقفة وأسرة أخرى تفققد للثقافة التربوية وذلك لأن فهم رغبات وميول الأو لاد بعطيهم القدرة على الابتكار و اكتساب الخبرات، فقلة الوعي للآباء تبدو مشكلة من أهم المشكلات التي تعوق المجتمع عن النهوض و التقدم على المستوى التربوي وقلة الوعي بالتعاون بين الأسرة والمدرسة لها أثار ها الكبيرة على المستوى التربوي التي تتؤثر سلبا على الطالب، لذلك نهيب بالآباء العمل على التعاون مع

$$
\text { [الدارسة في الأمور التي تصعب عليهم معالجنها. [ [ }
$$

ـالاستقرار الأسري :ليس هناك شك في أن الترابط الأسري يلعب دورا مهما في إعداد الطفل أو الفرد وتطبيعه اجتماعيا، بينما التصدع الأسري أو التفكل الذي يصيب الأسرة سواء بسبب الطلاق أو الزواج الثاني أو الموت كلها حالات لوضع اجتماعي غير مستقر يؤثر في عملية تنشئة الفرد ويؤثر في سلوكه وتصرفاته، فغياب الأب او الأم عن المنزل تعني غياب السلطة في البيت مما يؤدي إلى ظهور أطر اف أخرى كزوجة الأب أو زوج الأم إذا كانا مطلقان تقوم في اتخاذ القرارا، ومن الممكن أن تكون قرارات خاطئة تؤثر على سلوك الفرد وفاعليته في المجتمع لذا تؤكد الدراسات التربوية ضرورة اشتر اك الأب و الأم في التوجيه والإرشاد مما يؤثر إيجابا على نمو الفرد وفاعليته في المجتمع. [1] ـأسلوب الأم في معاملة الفرد: إن الطبيعة البشرية شديدة التعقيد فإن الآباء يختلفون أثد الاختلاف في تعاملهم مع الأولاد عن الأمهات فكل يحدد نوع المعاملة حسب ما ير اه مناسبا وخصوصـا الأمهات، حيث يتبعن أساليبا مختلفة مع أبنائهن حسب اختلاف المو اقف التي تحدث مع الولد أو البنت فكثير ا ما يتعرض الأبناء لمشاكل عديدة كمكلة الإمتناع عن الطعام أو مشكلة الإصرار على طلب شيء معين أو مشكلة الكذب والسرقة و العنف وكثير من المشكلات التي يمر فيها الطفل خلال نموه، حيث اثبتت الدراسات أنه يمكن للام أن تحقق نتائجا أفضل في التعامل مع هذه المشاكل وإيجاد حلول مناسبة لها أكثر من الأب، لذلك نرى أن معظم الأولاد تكون الأم مثلهم الأعلى، 
حيث يلجئون لها في الأوقات الصعبة لذلك تعتبر الأسرة وفي مقدمها الأمهات كونهن متابعات لما يحصل في البيت أكثر من الأب في مقدمة المؤسسات التي تنشئ الفرد خلال مر احله العمرية. [22]

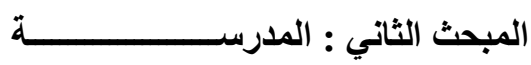

مفهوم ونشأة المدرسة وتطور ها.

مفهوم المدرسـة: تعرف المدرسـة لغـة مكان الدرس والتعليم والمدرسـة جماعة من الفلاسفة أو المفكرين أو الباحثين تعتنق مذهبا معينا، وتقول بر أي مشترك ويقال: من مدرسة فلان، على رأيه ومذهبه و الجمع مدر اس. [23] ولها تعاريف أخرى حسب آراء الباحثين منها: المدرسـة مؤسسـة اجتماعية تربويـة حظيت باهتمـام كثير من الباحثين منذ زمن طويل وذلك نظرا للأهمية الموكلة إليها من قبل المجتم، لأنها الحاضنة الأساسية للفرد بعد البيت منذ الطفولة في المراحل الأولية منها إلى أن ينت التخرج منها. [3] و هناك من عرّفها بأنها نظام اجتمـاعي كأي نظـام اجتمـاعي آخر تقوم على أسس ومبادئ معينة، من أهم هذه الأسس بالنسبة للمدرسـة السلطة المشروعة ،فالتلاميذ تابعون لمعلميهم بحكم أن هؤلاء المعلمين لديهم خبرة ومعرفة يحتاج إليها التلاميذ.

ومن التعاريف السـابقة يتبين لنا مدى أهمية المدرسة كمؤسسة تربويـة تكمّل عملية بناء الفرد جنبـا إلى جنب مع الأسرة لخدمـة المجتمع الذي يعيش فيه الأفراد لجعلهم أثخاص منتجين يخدمون أهلهم ومجتمعه وبلدهم ويسـاهمون في تقدمه، لذلك تؤدي المدرسة دور ا تكميليا لدور الأسرة في رفع دافعية التعلم لدى الطلاب وجعلهم متفوقين في در استهم لخدمة بلدهم. أمـا نشـأة المدرسـة: فالتربيـة عرفت منذ أن وجد الإنسـان على ظهر الأرض وكانت مرادفة للحياة نفسها، حيث كان كل فرد يكتسب السلوك الفردي للحياة عن طريق الاحتكالك المباثـر بالبيئة وعندما اخذت الحياة الاجتماعية بالتعقيد، حيث تحتم على الكبار في المجتمع أن يوجهوا اهتمامـا مقصودا بعملية التعليم لكن في الفترة الأولى اعتمدت التربية على مبدأ المشـاركة في حياة الجماعة في عدة قرون دون الاستعانة بمؤسسات تربوية متخصصه. 
ثم ظهر بعد ذللك أفراد من ذوي المهارات والقدرات فأسند إليهم بعض الأسرة مهمة تعليم أبنائهم مثلا، وإن كان تعليما عقائديا يعتمد على تعلم القراءة وخاصـة قراءة القرآن الكريم وكذلك الكتابـة، وهنـا يعتبر ظهور أول مدرسـة، ثم أخذت المدرسة بالتطور فنشملت علوم الدين و علوم دنيوية منل الطب و التخطبط و القانون... الخ.

أمسا في العصر الحديث فقد تميزت المدرسـة بتغيرات كبيرة، الأمر الذي صـاحبه تغير شـامل في النظر إلى المدرسـة كمؤسسة تعليميـة لعل من أهم هذه التغيرات التقدم العلمي المذهل، ونمو الاتجاهـات الديمقراطية الذي اسهم إسـهاما كبيرا في نشر التعليم وتعميمه لأن الديمقراطية تؤمّن بمبدأ تقدير قيمـة الفرد والإيمـان بذكائه ووجوب توفير الفرص عن طريق فتح المدارس لكافة الأفراد للحصول على التعلم، ولذلك وجب على الدولة أن توفره. [6]

خصائص المدرسة ومكوناتها:

تتميز المدرسة بخصائص ومميزات تنفرد بها عن غيرها من المؤسسات الاجتماعية وهي: المدرسـة بنيـة][ اجتماعية موسعة : فهي لم تعد مكانا للتعلم فقط بل تعدت ذلك حيث أصبحت تهتم بالتربية إضـافة إلى التعليم وهكذا المدرسـة تحاول أن تكون بيئة تربويـة تعليميـة ينشـأ فيها الفرد متزن الشخصية مضبوط العواطف عارفا مـا لله ومـا عليه من واجبـات وحقوق وقادرا على خدمـة نفسـه ومجتمعـه، كمـا تعمل المدرسـة على توسيع أفق التلاميذ،

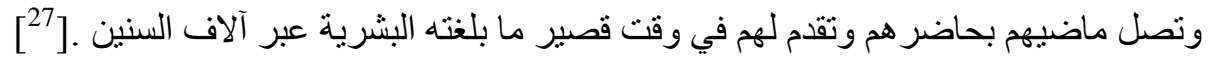
المدرسـة بنية تربويـة مبسطة: فهي تبسّط للطلب المواد المعرفية والمهارات المدرسية المتشـابكة، وتأخذ على عاتقها تصنيف المواد وتدريجها من السهل إلى الصعب ومن المجهول إلى المعلوم، وتعمل على غرس هذه المعلومات في الناشئة ليكون سلوكا يعيشوه ويقومون باه.

المدرسـة بنيـة تنقويـة: فهي تحاول أن تصفي مـا بعلق بالتلميذ من الفسـاد الفكري والخلقي وتخلق لله بيئة مفعمـة بالفضيلة و التقوى والاستقامة و إبعاد الأفكار المتطرفة التي تؤثر عليه بصورة خاصة والمجتمع بصورة عامة. المؤسسـة بنيـة تربويـة طاهرة: فهي تسعى إلى توحيد ميول واتجاهـات التلاميذ وصهر ها في بوتقة واحدة، بما يخلق واقعا اجتماعيا مناسبا للحراك الاجتماعي القائم على التعايش السلمي والتفاهم واحترام الآخرين وتفسح المجال لهم للتو اصل الثقافي فيما بينهم. [28] 
أمـا مكونـات المدرسـة تتكون المدرسـة حسب تقسيم البـاحثين في علوم التربية إلى قسمين: العامل المـادي والمتمثل في المبنى وملحقاته من مساطب جلوس ووسائل تعليمية.. إلخ ، العامل البشري المتمثل في الإدارة والمعلم والتلميذ. وتركز أهم البحوث التربوية على المكونات الأساسية والتي تتمثل في المعلم و التلميذ والمنهج الدراسي الذي يدرس للتلميذ. المعلم : المعلم إنسـان مرشد وموجـه وهو المختص الذي يعمل على إيصـال المعلومـة أو الخبرة التعليمية للمتعلم وذلك باستخدام وسـائل وأسـاليب فنية تحقق هذا الإيصـال والمعلمون يؤلفون جماعـة مهنية متميزة في المجتمع فهم القائمون على تر اث المجتمع ويحفظون هذا التراث وينقلونـه إلى الأجيال الجديدة، وهم بهذا يرسخون القيم والعادات والنظم والتقاليد ويينون الأمـة بينـائهم لأبنائها وهم يعتبرون بناة المستقبل، وفي وقتنـا الحالي يعد الباحثون العاملون على قطاع التربية والتعليم دور المعلم ذات أهمية كبيرة في العملية التربويـة والتعليمية وخاصـة في بناء شخصية التلمي، وهذا برجع حسب بعض الدراسـات إلى أن عدد السـاعات التي يقضيها التلميذ بين جدران المدرسة أصبحت أكثر من تلك التي يقضيها في البيت مـع و الديهـ ومن هنـا نرى الدور الكبير في المهمة الموكلة إليهه من حيث إن دوره لم يعد تلقينيا أو لتحفيظ التلاميذ بل أصبح تربويـا تعليميا في آن واحد.

فالمعلم هو المسؤول عن تنقيـة ثقافة وسلوك التلميذ وإعادة صياغة نمـاذج التفكير لديه صياغة سليمة تتماثسى، وخطط التتمية للمجتمع ومن هذا المنطلق فإن هناك مجمو عة من المهام ملقاة على عاتق المعلم تتمثل فيما يلي: إثارة الدافعية و الرغبة عند التلميذ للتعلم. التخطيط للارس مما يجعل الدرس سلسا يصل بسهولة إلى التلميذ. تقديم المعرفة المجتمعية مما يصب في توجيه التلميذ وجعله ينخرط بالمجتمع. توجيه النقاش بين التلاميذ و إدارته حيث يصبح حلقة وصل بين الطالب و الإدارة. الضبط و المحافظة على النظام. إرشاد التلاميذ إلى الثيء الجيد في المجتمع والحياة اليومية وغير الجيد منه ليمكن للطالب تجنبه. للتقييم و القيام بهذه المهام على السلطة التربويـة أن توفر لله مجموعة من الحقوق تسـاعده على تأديـة واجباته كسن فوانين تحمي المعلم وتسـاعده في التغلب على صعوبات الحياة، وكذلك على المعلم أن يتحلى بصفات جيدة كحبه لمهنته التعليم وتكوينه الجيد و إلمامـه بالعلوم الإنسانية خاصـة علم النفس والتربيـة والاجتمـاع من خـلال فتح دورات في هذه العلوم 
بالنسبة للمعلمين وأن يكون ذات شخصية قوية ومنضبطة وحامل لمثل عليا ولديه سعة صدر وتقبل الآخرين واحترام جهود

$$
\text { [التلامبذ. [ }
$$

ـالتلميذ : : ينظر للتلميذ على أنه وعاء يجب ملأه بالمعلومات فقط، وبتعبير آخر إنه غايـة العملية التربويـة ونلتمس استمرارية هذه الأفكار من خلال بعض الممارسـات للمعلمين داخل الصف، والتي ترى أن التلميذ طرف مستقبل للمعلومات لا غير ،دون مراعاته كطرف فاعل ومهم في سير العملية التربويـة، حيث إن التلميذ متعود على تلقي الأوامر والارشـادات منذ الطفولة من الثخص الأكبر منه والمتمثل بالأب والأم واعتبار كل مـا يصدر منهم شيء مقدس لا يناقش ويتقبل كما هو، وبالمقابل يعتبر المعلم نفسـه مجسدا لدور الأب الغائب بالنسبة للتلميذ في المدرسـة ومن هذ المنطلق يحاول المعلم إعـادة انتاج نفس الأفكار و الممارسـات التربويـة التي يعيشها مـع أبنائه في البيت ومنها اعتبار التلميذ مخلوق عاجز عن تقرير مصبره أو حتى المشـاركة في تكوينه، لكن يجب أن ينتبه المعلم أن هذه الأفكار والممارسـات التربوية تهمش التلميذ وتجعله سلبيا في العملية التربويـة خاصـة والمجتمع عامـة وقد تكون سبب في إضـعاف عزيمته وهز نقته بنفس، ومن هذا المنطلق برى بعض العلماء وجوب إثراك التلميذ في هذه العملية التربويـة، عن طريق الثراكة في إعداد خطة الدرس أو إعداد برنـامج رحلة مدرسية معينه أو نشـاط مدرسي معين مما يخلق لدى التلميذ نوع من الإحسـاس بالمسؤولية ويرى نفسـه عضوا فاعلا في هذه العملية التربويـة وتنمي لديه القدرة على بنـاء حياتـه ومجتمعه، أي أن التلميذ يكون حاملا لفكر نقدي لمـا يعطى لله من قبل المعلم، ممـا يدفع التلميذ إلى البحث الدائم ويوسع معلوماته وهنا قد سـاهمنا بصورة غير مباشرة بدفع التلميذ إلى الاجتهاد و الحصول على المعلومات وتجديدها مما يزيد من دافعية الطالب نحو التعلم. [ [ ـالمنـاهج|"] الدراسية المدرسية: يقصد بالمناهج الدراسية المواد التي يتم تدريسها للطلاب في المدارس، وهو الطريق الذي يسلكه المعلم للوصول إلى الأهداف التربوية من خلال إيصالها للطالب بشكل جيد وسلس. ويعرف المنهاج في التربية الحديثة بأنه: مجموعة الخبرات والتجارب التي توضع ليتعلمها الصنار، وتتصل المنـاهج الدر اسية اتصالا وثيقا بالأهداف التربوية هذا ما يجعل المنهاج يختلف باختلاف المو اد و الأفر اد و المجتمعات. [31] ونأليفها ينم على أسـاس أهداف المجتمع وثقافته بعد تحليلها على يد متخصصين بحيث نراعي احتياجات ومطالب النمو في كل مرحلة وتتماثـى مـع قدرات التلاميذ وميولهم وتراعي احتياجـات المجتمع المتجدة، والمنـاهج انشئت مـع نشوء المدارس 
النظاميـة حيث كانت في البدايـة تهتم بجانب واحد من جوانب النمو عند التلميذ وهو جانب النمو العقلي وتهمل الجوانب الأخرى كالنمو الجسمي و الاجتماعي.

وبتطور المجتمع بدأت المنـاهج تهتم شيئا فثنيئا بـالنواحي الجسمية والاجتماعية والنفسية وأصبح التلميذ محور العملية التربوية بدلا من كون المـادة الدراسية هو المحور الرئيسي، أي تكيف التلميذ مـع الحياة المحيطة والغايـة التي يريد المجتـع بلوغها لذلك يعتبر المنهج الدراسي جانب مهم في دافعية التعلم لدى الطالب كونه يهتم بالتلميذ ويطور التلميذ وربطه بثقافة المجتمع التي يعيش فيه التلميذ.

وظيفة المدرسـة كنظام اجتمـاعي: إن للمدرسة وظائف كثيرة لا تعد ولا تحصى ولكن سوف نأخذ بعض هذه الوظائف وأهمها تأثيرا على المجتمع، حيث للمدرسـة وظيفة إعـادة إنتاج قيم مشتركة من خلال كونها مؤسسة تعليميـة لديها دور مهم في تلقين الأطفال القيم الأخلاقية التي يخضـع لها المجتمع، ولديها وظيفة أخرى أيضـا في كون المدرسـة تسـاعد الفرد على الإندماج ضمن مجتمعه من خـلال كون المدرسـة جهاز إيديولوجي وطني تعدل على دمج كل فرد بالعمل في مختلف القطاعات الاجتماعيـة ومزاولـة أي نشـاط اجتمـاعي، أي أنها تعمل على التوفيق بين النظام المدرسي والنظسام الاجتمـاعي.

وتعمل المدرسـة على تهيئة الفرد للدور الاجتمـاعي من خـلال تهيئة الطالب لعمل مستقبلي من خلال تنميـة مواهبه التي يحبها فالطالب لبس من المفروض أن يخرج من المدرسـة طبيبا أو مهندسـة، حيث يؤكد أغلب الباحثين على مراعاة ميول الطفل و اتجاهاته وتنميتها لكي يصبح إنسانا يحب عمله الذي اختاره هو ليس الذي تختاره الأسرة لله، ويكون منتجا فيه أكثر من غيره، وهنا تأتي وظيفة أخرى للمدرسـة وهي تربية الاختيار لدى الطالب من خـلال استراتيجيات يتعلمها من المنظومـة التربوية التي توفر ها المدرسة. ومن وظـائف المدرسـة الأخرى تدعيم التربية السلوكية للطالب من خـلال تكوين الفرد وتنكيله وتوجيـه أسلوب حياته والاستفادة من إمكانياته وقدراته لاكتسـاب الخبرات التي تسـاعده على النمو في الاتجـاه السليم مدـا يجعله نافعا لنفسه ومجتمعـه، وكذللك تأتي وظيفة المدرسـة في تدعيم التربية الأخلاقيـة للطالب لكون المدرسـة جزء من المجتمع لللك يمكننا اعتبار وظيفة المدرسة الأخلاقيـة هي وظيفة لا غنى عنها إذا أردنـا مجتمعا أخلاقيا فلا بد أن تقوم المدرسـة بتدعيم القيم الأخلاقية في نفوس الطلاب ومقاومـة مـا هو عكس ذلك، أما دور المدرسـة في تنميـة تدعيم التربيـة الإبداعية لدى الطالب

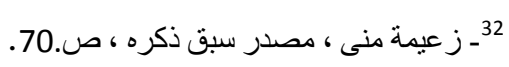




و الاهتمـام بالتعليم و التعليم الإبداعي عن طريق نهيئة فرص كافية لخلق أفراد قادرين على فعل أشياء جديدة ليست متكررة، وكذللك للمدرسـة دور كبير في تدعيم التربيـة القوميـة لدى الطالب حيث تعتبر المدرسـة الأداة التي توحّد أبنائها وتجمعهم على وحدة الهدف لذا يتحنّم على المدرسـة أن تضـع نصب عينها لتعد أبنائها للمواطنة العربيـة التي تتجلى بالإيمـان العميق بالقومية العربية كثيء حتمي وضروري434

أمسا الجانب الأهم من وظائف المدرسة تأتي في وظيفتها كنظام اجتماعي، حيث تشهد المجتمعات المعاصرة في كثير من المجتمعات في العالم تغيرات سريعة ومتعدد، وهي تحنّم على المدرسـة مراجعة علاقاتها مـع التلاميذ وأسـاليب تعليمهم والمناهج التي تدرس لهم وطرق التعامل معهم للتغلب على الآثار السلبية لهذه التغيرات التي تفاقمت بسبب انشغال الوالدين عن الأولاد بسبب كثرة أعمالهم وازدياد متطلبات الحياة فأصبح على المدرسـة أن تقوم بدورها وتحقق أهدافها، فتربية الأو لاد في هذا العصر أصبحت مسؤولية كبيرة يقع عاتقها على المدرسة. [35] كمـا أن المدرسـة نظسام اجتمـاعي بحكم كونها منظمـة تقوم على الأفر اد ولها أيضـا طرقها وتقاليدها الخاصـة التي تشكل ثقافتها وبالتالي تحدد سلوك المعلمين و التنلاميذ وغير هم من المتصلين بالمدرسـة كما أن ثقافة المدرسـة هي التي تحدد معاير السلوك الجيد والرديء و النجاح و الفشل ومـا يتصل بذللك من اهداف ووسـائل فأن هذه الثقافة تحتوي على عناصر غير متجانسـة بل متضـاربة أحيانـا، فالتلاميذ على سبيل المثنال قد تكون نظرتهم أن لا يجهدوا نفسهم إلا بمقدار مـا يكفل لهم الحد الأدنى من النجاح في حين أن معلميهم يتوقعون منهم أن يبذلوا قصارى جهدهم في تحصيل العلم [36

لذلك تحرص المدرسـة على تزويد زيادة النشء بطريقة التفكير السليم المعتمد على الملاحظة والتفسير واتباع القوانين و الفكر السليم التي تتمانتى مـع طبيعة المجتمع الموجودة فيه تلك المدرسـة لأن المجتمع يقوم على مجموعة من الاتجاهـات الفكريـة والاجتماعيـة لذلك على المدرسـة أن تشـارك في رسم هذه الاتجاهات الفكريـة والاجتماعيـة ممـا يجعلها نظامـا اجتماعيا

$$
\text { مهم، يؤدي دوره في المجتمع. }
$$

\section{أهمية المدرسة في عملية التنشئة]] الاجتماعية وتكوين شخصية الطالب:}

بالرغم من أن المظاهر الأولى للتنشئة الاجتماعية تبدأ وتترعرع في جو الأسرة إلا أن الأسرة لم تعد تستأثر وحدها بتلك التنشئة في عالمنـا المعاصر وذلك نتيجة للتصنيع الذي أدى بدوره إلى تحديث المجتمعات وتطورهـا حتى أضعف بذللك دور 
الأسرة ويضـف أثر الأسرة في تلك التنشئة عندما تصبح فرص التعليم متاحسة للجميع وتصبح المؤسسات التعليمية المختلفة بما فيها المدرسـة والجامعة هي المدخل الطبيعي لكسب الرزق، وهذا مـا يحدث الأن في أغلب المجتمعات المعاصرة وخاصـة في البلدان التي تخطط لنفسها لتتطور من مجتمعات ناميـة لمجتمعات متقدمة وتتحول من مجتمعات زراعيـة إلى


وقد زاد أثر الأسرة في التنشئة الاجتماعيـة أيضـا اضمحلّ أثر الوراثة في تحديد المكانة الاجتماعيـة وأصبحت المكانة الاجتماعية تكتسب عن طريق التعلم، وبذللك أصبح الفرق بين الأسرة والمدرسـة في التنشئة الاجتماعية هو أن الفرد يكتسب مكانته في الأسرة عن طريق الجنس والسن وصفاته الخاصـة بينما في المدرسـة يكتسب مكانته الاجتماعيـة عن طريق المنافسة و الامتحانات التي تؤهله بعد ذلك للمهنة في المستقبل وتتصف هذه المهنة بالمكانة الاجتماعية. لايوجد أي مؤسسـة اجتماعيـة تمتلك من الفرص مـا تمنلكه المدرسـة في تشكيل نمو الطفل المراهق وتتضـح أهميـة المدرسـة في زيادة عدد الساعات التي يقضيها الطالب في المدرسة، وتلعب المدرسة دور بارزا في عملية التنشئة. إذ تأخذ المدرسـة على عاتقها في المجتمع الحديث مهمة تهيئة الصـار تهيئة اجتماعية من خلال نقل الثقافة والقيم والمعايير التي تشتمل الأسس الإيديولوجية لتراث المجتمع الثقافي.

وتلعب المدرسة في المجتمع الحديث دورا هاما في تعليم الاتجاهات و المفاهيم والمعتقدات المتعلقة بالنظام السياسي. وكذلك تلعب المدرسة دورا بارز ا في مساعدة الأطفال على تعلم ضبط انفعالاتهم والتعامل مع مر اكز السلطة وطريقة حل مشكلاتهم، وتلعب المدرسة دورا هاما في تكوين وبناء القيم والمعايير و اكسابها للطالب فالمدرسة بنية اجتماعية متميزة فيها مكانات وأدوار اجتماعية معددة.[38] لكي تصبح التنشئة الاجتماعية داخل المؤسسات التعليمية فعالة وتزيد دافعية التعلم لاى الطالب فان عليها الاتي: - - أن تعمل على إشر اك الطالب في ممارسات تساعده على أنماط السلوك السوي. - - أن تعمل على اكساب الطالب القيم و المعايير الخلقية التي يحث عليها مجتمعنا وديننا الحنيف. أن تعمل على تعليم الطالب المهار ات التي يعمل بها المجتمع أو التي ينبغي أن يعمل بها. أن تعمل على إعداد الطالب للمستقبل وذلك من خلال قيام المدرسة بتعريف الطلاب بالمتغيرات لمستجدات الاجتماعية والثقافية والتكنولوجية وغيرها التي تواجه مجتمعاتهم وتفسيرها لهم. والاهتمام بميول الطالب 
ور غباتهم وحاجاتهم وقدر اتهم واستعداداتهم و الفروق الفردية بينهم والعمل على اكتشاف المو هبين والمبدعين ورعايتهم والاهتمام بهذه المو هبة وتنميتها، وأن تعمل على تأسيس القدوة المثالية من خلال المدرسين الجيدين القادرين على التأثير بشخصية الطالب.[39]

\section{المبحث الثالث: دور الأسرة والمدرسة وعلاقتهما بالنجاح المدرسي}

تعد الأسرة والمدرسة من أهم المؤسسات التي تتولى مسؤولية التنشئة للطالب أو الفرد حيث تحرص الإجر اءات التربوية الحديثة على توطيد العلاقة بين هاتين المؤستنين على اعتبار أنهما تلعبان دور ا تكامليا في تربية الطلاب وتعليمهم ولكن ما يحصل أن العديد لا يزالون لا يدركون أهمية التو اصل بين الأسرة و المدرسة و إن نوفرت الوسائل لذلك. [0] لذا سنتطرف في هذا الفصل إلى أهمية وأهداف التعاون بين الأسرة والمدرسة التي تسهم في التنشئة الاجتماعية الجيدة في جعل الفرد يشعر بمسؤولياته اتجاه نفسه واتجاه الآخرين عن طريق تعليمه الأدوار الاجتماعية والمعاير الاجتماعية التي تحدد هذه الأدوار إذ يتعلم كيف يسلك سلوكا اجتماعيا مقبو لا عن طريق علاقاته الاجتماعية وفهمه للآخرين ودور كل من الأسرة والمدرسة في هذا الجانب. [11] حيث بينت أهم الدراسات الحديثة أن الأسرة في الوقت الحاضر أصبحت غير قادرة على القيام بجميع وظائفها وبالثكل الذي عرفناه سابقا، لذا فقد أوجد المجتمع الكثير من المؤسسات المساعدة للأسرة في عملية التنشئة الاجتماعية وجعل هذه العملية تتمو ثمار ها بشكل

$$
\text { سليم من جميع النواحي النفسية والاجتماعية ومن ضمن هذه المؤسسات هي المدرسة [24] }
$$

مما تقدم نستطيع أن نلخص أن الدور التربوي لا يعتمد على الأسرة فقط ولا على المدرسة لوحدها أيضا، وإنما هذا واجب الاثثين معا أحدهم يكمّل الآخر في العمليات التربوية و الاثنان يجعلان الطالب باستطاعته الاعتماد على نفسة ويخدم نفسه ومجتمعه وسوف نأخذ دور كل منهما على الدافعية التعليمية لدى الطلاب. دور الأسرة في التحصيل الاراسي للطالب :

الأسرة كتنظيم اجتماعي لها الدور الأساسي في التنشئة الاجتماعية ولا سيما في مجال التحصيل الدراسي فقد بينت الدراسات إن نسبة [43] الارتباط بين النظم الأسرية ومستوى التحصيل الدراسي في المدارس الأمريكية بلغت 43\% وفي المملكة العربية السعودية50\% ولهذا تتضح أهمية النظم الأسرية في تعزيز استمرارية التأثير على مستوى تحصيل الطالب على الرغم من الاختلاف في المجتمعات و الثقافات. 
ـالعلاقة الإيجابية بين الو الدين و الطالب من العوامل المهمة المؤثرة في التحصيل الدراسي إذ تشير الدراسات المنشورة إلى أن الجو. العاطفي للأسرة الذي يسوده التقبل و التسامح و المودة و الحب و الثقة و المشاركة و التعاون .

ومن أهم العوامل المؤثرة إيجابا في تكوين شخصية الأبناء ونموهم النفسي والاجتماعي وأساليب تكيفهم مما يؤدي إلى زيادة دافعيتهم في التعلم والتحصيل الاراسي:

ـأسلوب الحماية الزائدة: يعتبر أسلوب الحماية الزائدة في معاملة الو الدين للطالب شيء مأتر على الطالب، حيث يقوم أحد الوالدين أو كلاهما نيابة عن الطفل بالو اجبات أو المسؤوليات التي يمكنه القيام بها معتقدين أن هذا الأسلوب يخفف من الحمل على كاهل الطالب مما يؤدي بالنهاية إلى أنهم يحمونه من التعب الذي يصيبه بل يتعدى ذلك إلى التدخل في كل شؤونه مما يؤثر سلبا على نشاطه المدرسي ودافعيته على التعلم.

ـاستقرار الجو الأسري : حيث يحتاج الطالب إلى جو أسري مستقر تسود فيه المحبة والأمان وتكون العلاقات الأسرية حسنة حيث يكون الو الدان قادر ان على فهم حاجات أبنائهم والعمل على إشباع هذه الحاجات ولكن بطريقة مقبولة وفي حدود مصلحة الأبناء فالطالب الذي يربى في هذا الجو الحميم من النظام و الهدوء يتابعون حياتهم الدراسية دون مشاكل [44] - تعامل الوالدين مع الطالب : إذ تبين الدراسات أن للوالدين في تعاملهما مع الطفل درجة كبيرة من التأثير على التحصيل الدراسي ودافعية التحلم لديه حيث أن مر اعاة الو الدان متطلبات الطالب وحاجاته النفسية والاجتماعية تزيد من دافعيته نحو التعلم، حيث إن بعض من الآباء لا يلقي إلى مثل هذه الأمور أي أهمية ، مهملين بذلك حاجات الطالب، وذلك لأن للطالب مشاعر وأحاسيس يكون من خلالها نظرته إلى ذاته و إلى الآخرين.

_الحرمان][] العاطفي : حيث توصل عالم الاجتماع بال إلى أن الذين يعانون من صعوبات القراءة يتميزون بالحرمان العاطفي حيث يتميز هؤلاء الطلاب بعدم القدرة على التركيز والانتبا، ووصفوه خارج سرب المتفوقين، بينما لم يظهر المتفوقون دراسيا مثل هذه المشاكل. حيث يرى أن الحرمان العاطفي قد يؤدي بالطالب إلى ضعف الثقة في نفسه ويؤدي بدوره إلى رفض المعلمين له. ـ الإهمال من قبل الأسرة للطالب : ويسبب هذ الإهمال مردودا دراسيا رديئا لأن الإهمال للطالب وخاصة من قبل والديه يؤدي إلى تعطيل جزئي أو كلي في العمليات العقلية، فالثخص المتونر لا يملك القدرة على التذكر كما أنه لا يدرك إدراكا سليما للمواقف التي تو اجهه وتصبح جميع العمليات العقلية معطلة لديه، إذ تصبح العلاقة السليبة مع والديه خسارة تدريجية لجاذبيتهم ويصبح وجودهما عديم النفع يخلو من الدعم المعنوي في حياة الطالب، مما يؤثر سلبا في تحصيله الدر اسي ودافعيته على التعلم 45. 
ـ أسلوب القسوة[*] : ويتمثل استخدام أساليب العقاب البدني و التهديد به وذلك ما يؤدي إلى إثارة الألم الجسمي أسلوب أساسي في نربية الطفل، ويأتي ذلك بطريقة الإسراف في العقاب البدني الضرب، أو إثارة الألم النفسي وقد يكون ذلك إثعار الطالب بالذنب كلما أتى سلوكا

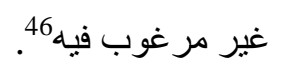

_أسلوب التسلط[”] : يقوم هذا الأسلوب على مبدأ الإلز ام والإكر اهو الإفر اط في استخدام السلطة الأبوية في التعامل مع الطالب وخاصة الطالب في المرحلة الثانوية حيث لا يسمح له بإبداء رأيه أو توجيه انتقادا وإن حدث ذلك يكون مصدر للسخرية والضحك مما يؤدي إلى فقدان الثقة بنفسه وإحباطه، مما يؤثر سلبا على تحصيله الدر اسي ودافعيته على التعلم 47. هذه أهم أساليب الأسرة في التعامل مع الطالب وتأثثر ها على تحصيله الدراس ودافعيته للتعلم حيث بينا دور الأسرة في دفع الطالب نحو التعلم وتحصيل الدراسي. دور المدرسة في التحصيل الاراسي للطالب:

كما إن للأسرة دور في التأثير على الطالب وتحصيله الدراسي ودافعيته على التعلم أيضا للمؤسسة التعليمية، وأولها المعلم له دور أضـا في هذه الدافعي، وسوف نبين أهم الأساليب التي يجب على المعلم أن يتبعها لدفع الطالب على التعلم. _أسلوب السياسات المحفزة النافعة: مساعدة الأطفال على الوصول إلى أهدافهم ـ وخاصة الذين لايهم قلق على قدراتهم الدراسية و على التعلم، أما إذا كانوا يعانون من مشاكل تركيز الانتباه فيمكن تعليمهم الحو افز النفسية فمقعد الدراسة يستعمل من أجل التعلم وليس من أجل شيء آخر وأحلام اليقظة يجب أن تتم في مكان غير مقعد الدراسة، وكما يمكن استخدام عبار ات تساعد على التركيز مثل( استمر ) (سوف تحصل على ما تريد ) ( لا تيأس) أما إذا شعر بالنعاس فعليهم استخدام مصباح أكثر إضاءة مع أخذ وقت للاستر احة وكذلك جو ائز نقدية على كل خطوة نحو الإنجاز وتحقيق الهدف48. _تغير مفهوم الطالب عن نفسه: وذلك بحثه على التوقف عن التفكير السلبي عن نفسه ليكون ناجحا ومسئو لا، وأن يكون لاى الطالب خيالا مشجعا إيجابيا عن إنجاز اته مما يدعم الثقة في نفس الطالب وتحفيزه على الجد و المثابرة ودفعه إلى التعلم. _تقديم أفضل الظروف المحبية للاراسة: إن الواجبات المدرسية البيتية هي مسئولية الطالب و على المعلم أن يراعي توفير أفضل الظروف المحببة للار اسة مثل إعطاء الو اجبات البيتية بشكل لا يزيد من عبء الطالب وخاصة طالب الثانوية ومر اعاة المو اد المنهجية 
الأخرى وكذللك أيام الامتحانات الفصلية يجب على المعلم أن يراعي ظروف الطالب وعدم التأثير على امتحاناته وسهولة الوصول إليها. - توظيف منجزات العلم التكنولوجية في إثارة فضول وتثويق المتطلم، كمساعدته على التعلم من خلال اللعب المنظم، أو التعامل مع أجهزة الكمبيوتر ، فهي أساليب تساهم كثير أ في زيادة الدافعية للتعلم لأقصى ما تسمح به قدرات المتعلم، مع تتمية التعلم الذاني وتحمل مسئولية عملية التعلم، وتتمية الاستقالية في التعلم. أساليب معاملة المدرسين للطلاب وعلاقتها بالنجاح المدرسي للطالب:

ـ أن يكون المعلم مستقبلا ومشجعا : ينبغي أن يشجع الطلاب على المحاولة وأن يبدلو ا أقصى جهد وأن يتحملوا الإحباط. وأن يتقبل المعلمون الاستماع للطلاب وتثجعهم ودعم محاو لاتهم على الفهم وكما ينبغي تجنب النقد و التهكم وعدم ربط قيمة الذات بالإنجاز .بل يجب تقبل الطالب بالرغم من فثله في المدرسة ويكمن الحل في مساعدة الطالب في وضع أهداف حقيقية وتثجيعهم في التغلب على العو ائق التي تعترض هذه الأهداف وبذلك ينظر للمعلمين كمصدر من مصادر الدعم والتشجيع أكثر من كونهم مجرد ناقدين. ـ اتباع أسلوب حل المشكلات الإيجابي: تسنطيع أن تشارك الطلاب في اكتثاف كيف ولماذا تعمل الأشياء. و هذا الأسلوب الإيجابي للتعلم حيث تسأل وييحث الطالب عن الجواب وتجمع الحقائق وتتظم وتصنف وتلخص المناقثة .فمنذ سن مبكر بعلم الأطفال كيف يجهزوا أنفهم للبيئة ينعلمون كيف يركزوا انتباههم وكيف ينجزوا الثيء الذي بدأوا فيه، فأهية التعلم يجب أن تتعلم كيف يطور الأطفال الرغبة في التعلم وتفسر لهم عملية التعلم و إنهم يتعلمون بالتجربة وتطبيق الههارة. - استعمال نظام الحوافزן *|القوية: الطلاب الذين يفتقرون الدافعية ينبغي أن تكون الحوافز لها آثار ا فورية على الانجاز في غرفة الصف، فمثلا انتباه الأب و المعلم يمكن أن يكون دافعاً قويا نحو التعلم إذا ما تم استغلاله بشكل جيد ـ الككافآت متتوعة منها ما هو امتداح لفظي أو استعمال التلفاز أو الحاسوب أو رحلة أو ركوب سيارة أو إعطاء عدد من الدرجات للطالب لتميزه في إلقاء موضوع معين و هناك الكثبر من الأشياء تعطى للأطفال على عمل أخلاقي أو إنجاز الوظائف أو الحماس في المشاركة في الصف ـ هذا النظام فعال عندما يتعاون البيت و المدرسة معاً مع العلم أن نظام الحو افز الجيد يمكن أن يكون فعال مع المراهقين حتى تتولد لديهم الدافعية فإحضار المر اهق علامة يومية أو تقرير ناجح عن أعمال مدرسية فسيقود ذلك إلى جو ائز إيجابية اختار ها الطالب سلفاً .فالمقاييس اليومية و التغذية الر اجعة تزيد من التعلم ومن الدافعية. 


\section{أساليب معاملة الوالدين للأبناء وعلاقته بالنجاح المدرسي للطالب:}

تعتبر الاساليب التي ذكرت سابقا من أسلوب الأسرة أو المدرسة أو المعلم و أثزرها على التحصيل الدراسي للطالب و الزيادة الدافعية لدى الطالب في التعلم مكملة للجز ء الأهم في عملية تعلم الطالب و هو أسلوب معاملة الو الدين للأبناء و علاقته بالنجاح ودافعية التعلم لديهم حيث تنعكس هذه المعاملة سلبا أو إيجابا على المحاور السابقة ونظر الأهميتها سوف نأخذها بشيء من التفصيل أكثر من المحاور السابقه: ـ المساندة الوجدانية : مما لا شك فيه إن الأطفال الذين ينشؤون تحت رعاية آبائهم وفي ظل علاقات عاطفية طيبة يميلون إلى تنمية الصفات الإيجابية من الناحية الاجتماعي، أما التهديد بالحرمان من الدعم العاطفي أو القبول الوالدي هو أسلوب عدواني قد يسلكه الآباء في معاملة أو لادهم و هذا بالتالي يوثر على مسار تنشئتهم الاجتماعية السليمة، لذلك يجب أن يكون الدعم العائلي و المساندة الوجدانية من أولويات الو الدين لتنشئة سلوك ابنهم وتصرفاتهم ومعالجة مشاكل الأبناء من خلال إظهار الحب والتشجيع له و لإنجاز اته والاستجابة له ولطلباته وأن يكون التوجيه له برفق ومودة ، وتعتبر المساندة الوجدانية أهم الأسباب السوية في التنشئة الاجتماعية ولها أثر كبير على تنمية شخصية الأبناء ويعبر عنها بمدى الحب الذي يبديه الوالدين والدعم العاطفي لله من خلال تصرفاتهم نحوه في مختلف المو اقف اليومية. وأوضحت بعض بحوث علم النفس الأسري أن الأطفال الذين يمرون بخبرات أسرية تحمل في طياتها الحب و القبول والمساندة الوجدانية هم أكثر ثقة بأنفسه وأكثر تعاون مع الآخرين من هؤ لاء الذين يعيشون جو أسري ينعدم فيه الحب و الإحساس الوجداني. [15] ـ الضبط الوالدي : ويقصد به الاعتدال و عدم الإفر اط في وضع القيود في التسيب لكي لا يؤدي هذا إلى قصور في نمو الطفل الاجتماعي ولذك يرى بعض الباحثين إنه من الأفضل أن يكون الآباء غير منطرفين وأن يسمحو لأبنائهم بقدر من الحرية إلى جانب فرض القيود والضوابط بحدود معقولة حيث يعتبر هذا النوع من الوالدين بقدتهم على المرونة في الضبط ولهم دور كبير في تحصبل ابنائهم الدر اسي، و اعتبر ان مثل هذا الأسلوب في معاملة الأبناء من شأنه أن يخلق أبناء يشعرون بالثقة بالنفس والاستقلال الذاتي مما يهيئ لهم القدرة على تفهم بيئتهم وتكوين علاقة اجتماعبة ناجحة مع أقرانهم دون قلق أو عصبية عكس تلاك الأسر التي تشوبها أساليب التسلط

ـ تذبذب الو الدين : إن ادر اك الطفل من خلال معاملة والديه له إنهما لا يعاملانه معاملة واحدة في المواقف المتشابهة هذا يعني التذبذب في المعاملة و هناك تذبذب قد يصل إلى درجة التناقض في مو اقف الو الدين و هذا أسلوب يجعل الطفل غير قادر على توقع ردة فعل و الديه ازاء سلوكه، ويشير الباحثون في هذا المجال إلى أهمية ثبات أسلوب الآباء في معاملة البناء حتى يقل ميلهم إلى الانحر اف لاى الأولاد الذين ينتمون إلى أسر ذات أساليب تعامليه ثابته سواء في العقاب أو المساندة، لذلك اتباع أسلوب التذبذب في المعاملة غالبا ما يترتب عليه شخصية ازدو اجية منقسمة على نفسها وهي موجودة في حياتنا اليو مية ونصادفها كثير ا حيث إن الذي يعاني من التذبذب في معاملته يكبر 51 - نجاح احمد محمد الدويك ، المعاملة الو الدية و علاقتها بالذكاء و التحصيل الدراسي لاى الاطفال في مرحلة الطفولة المتأخرة ، رسالة ماجستير ، كلية التربية علم




و غالبا ما يصبح مذبذبا ومزدوج الثخصية هو الآخر في معاملة الناس أي تنعكس معاملة والديه على شخصيته في التعامل مع المواقف نفسها في حياته اليو مية.

ـ تسامح الوالدين: ويعني أسلوب الفراط في التسامح و التساهل مع الأبناء مما يؤدي إلى مشكلات في التوافق الثخصي والاجتماعي لاى الأولاد إلى جانب ميل الأو لاد إلى العدوان والتسلط لأنه يتوقع التساهل من قبل والديه إزاء أب سلوك عدواني او خارج عن المعاير الاجتماعية وما يلبث أن يتعرض الطفل إلى الاضطر ابات النفسية والعصبية نتيجة للإحباطات عند الاحتكاك بالو اقع فهو لم يعتاد الاحباط في طفولته المبكرة وقد تتخذ هذه الاضطر ابات النفسية والعصبية أشكالا متعددة مثل أزمات عصبية وقضم الأظافر وثورات الغضب.

و مما سبق من سرد للأساليب المتبعة من قبل الأسرة والمدرسة والمدرسين والآباء و الأمهات نلاحظ أن دور دافعية الطالب إلى التعلم لا ينحسر بجة واحدة ولكن يجب أن يكون هناك تعاون بين الأسرة والمدرسة للوصول إلى الدافعية الجيدة للطلاب وهناك عدة مجالات للتعاون بين المدرسة والأسرة ومن هذه المجالات ما يأتي : ه اشتر الك الآباء في أنشطة المدرسة.

• إرسال تقارير مختصرة للآباء ونماذج من عمل ابنائهم. اللقاء مع الآباء و الاتصال بهم عن طريق المكالمات الهاتفية أو اللقاءات. زيار ات المدرسة و المعارض الفنية و الثقافية المختلفة. تسجيل أنشطة المدرسة بالصوت والصورة وإرسالها إلى الآباء، الإشراف على الرحلات المدرسية من قبل الآباء وتقديم خدماتهم الاستشارية للمدرسة و أيضا المساعدة و المشاركة في البر امج التعليمية [54] وفي النهاية لا يسعنا إلا أن ندعو من الله أن نكون قد وفقنا في سرد بعض المشاكل في الأسرة والمدرسة التي قد تساعد دائرة التعليم الديني في حل بعض مشاكل الطلبة في الثانويات الإسلامية. 


\section{و أهم النتائج و التوصيات التي توصلت اليها هي: \\ أولاً :النتائج:.}

1- تبين أن دور الأسرة هو الدور الأهم من بين المحاور، لكون الأسرة هي المحور الاساسي في تكوين الفرد منذ الطفولة وحتى عبور دور المر اهقة صعودا إلى المرحلة الجامعية وأن تأثثر الأسرة المنمثلة بالوالدين في تعاملهم مع الأبناء له الدور الكبير في عملية التنشئة الاجتماعية ورفع الدافعية للأبناء في التحصيل الدراسي. 2- يأتي دور المدرسة في عملية التنشئة الاجتماعية بعد الأسرة وهنا نحن لا نقلل من دور المدرسة ولكن تبين أن الأسرة هي الأهم ومن بعدها المدرسة ويأتي دور ها من خلال إدخال الوسائل التعليمية المتطورة في عملية التعليم مما يساعد على رفع مستوى الدافعية لاى الطلاب في التحصبل الدراسي. 3- إن تعاون المدرسة و الأسرة في عملية التنشئة الاجتماعية لها دور كبير جدا في رفع الدافعية لدى الأبناء في التعلم وخاصة في المرحلة الثانوية وذلك من خلال حل المشاكل التي تو اجه الأبناء و المساعدة في حل هذه المشاكل من خلال التعاون بين الآباء والمدرسة و الوصول إلى افضل النتائج في التعلم وتجاوز هذه المرحلة الحرجة للأبناء وهي مرحلة المر اهقة. 4- إن وجود المرشدين الاجتماعيين و النفسيين في المدارس في حل مشاكل الطلب في المدارس حيث إن هؤ لاء لهم خبرة كبيرة في حل المشكلات التي تواجه الطلبة لكونهم ذو اختصاص ومطلعين على أغلب مشاكل المجتمع وبالتالي يساعد هؤلاء المرشدين الاجتماعين الآباء في محاولة التغلب على مشاكل الأبناء و الوصول لأفضل النتائج في عملية التعلم لدى الطلبة. 5- إن دور المؤسسات الإعلامية و الاذاعية له دور كبير في عملية التعلم حيث يجب على هذه المؤسسات بث برامج تلفزيونية عن طرق معاملة الآباء و المدرسين في حل مشاكل الطلبة والوصول بالعملية التربوية إلى أرقى مستوى من خلال باحثين اختصاص في مجال الاجتماع و علم النفس. 6- إن عملية المكافأت التي يستخدمها الآباء أو المدرسون لها دور كبير في دفع الطلاب إلى التعلم وحب المدرسة وبالتالبي زيادة دافعية التعلم لدى الطلبة 
ثانياً :التوصيات:

$$
\text { من خلال فقرات المباحث الثلاثة السابقة نوصي بما يأتي: }
$$

1 ـ تخصيص اوقات كافية من قبل الآباء للجلوس مع او لادهم والحديث معهم عن احو الهم ومشكلاتهم التي تواجههم في المدرسة وحياتهم

2- توجيه وسائل الاعلام المرئية و المسموعة ونشر بر امج نوعوية عن كيفية التعامل مع الأبناء وخاصة المر اهقين منهم.

3- من الضروري الاهتمام بالأبناء في مرحلة التعليم الثانوي من قبل المدرسة والأسرة على حد سواء على اعتبار أنهم يمرون بأصعب مرحلة عمرية و هي مرحلة المر اهقة وما يتبعها من تغيرات سيكولوجية وفيزيولوجية. 4- ضرورة التواصل بين الو الدين والمدرسة ومعرفة احتياجات التلاميذ النفسية ومعرفة مشكلاتهم التي يعانون منها في البيت و المدرسة و التعاون بين المدرسة والأسرة لحل تللك المشاكل و التعرف على مدى سلامة سلوكهر. 5- إقامة مسابقات داخل المدرسة بحضور أولياء الأمور لاكتثاف مو اهب الطلاب وتتمية مو اهبهم وتوجهاتهم وتشجيعها من قبل المدرسة و أولياء الأمور بما يخدم الطالب وزيادة دافعيته للتعلم وحب المدرسة مما يصب في مصلحة المجتمع عامة. 6- ضرورة وجود أخصائيين اجتماعيين نفسيين في جميع الثانويات وذلك لمساعدة الوالدين في توجيه الأبناء ومساعدتهم في حل مشكلاتهم مما يساعد على تحقيق الدافعية لدى الطلاب في التحصيل الدراسي. 7- نشر مبدأ الثواب و التركيز عليه أكثر من مبدا العقاب؛ لأن الجو ائز والمكافأت حتى ولو كانت بإعطاء الطالب درجة أو درجتين زيادة نظر المجهود قام به وتنبيهه إلى الخطأ الذي يقع به بدلا عن توبيخه سواء كان من قبل الأسرة أو المدرسة له أثر كبير في رفع الدافعية لدى الطلاب في المدرسة وحبهم لها بدلا من كر ههم لها. 


\section{قائمة المصادر والمراجع:}



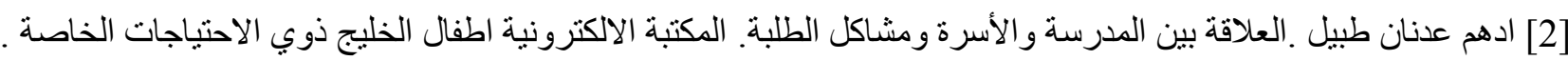
[3] الكندري ،احمد محمد مبارك ـ علم النفس الاجتماعي و الحياة المعاصرة .الكويت : مكتبة الفلاح للنشر و التوزيع،ط ث، 1995. [4] الالوسي ،جمال حسين .علم النفس العام .بغداد : وزارة التعليم العالي والبحث العلمي ، جامعة بغداد ، كلية التربية ، 1989. [5] الشعال ،الثيخ الطبيب محمد خير ـ الأسرة والتربية .دمثق : دار افنان للنشر،2006.

[6] القائمي ،علي ـ الأسرة والطفل المشاكس .بيروت : دار النبلاء للنشر ، 1996.

[7] عمر احمد همشري .التنشئة الاجتماعية للطفل. الاردن: دارصفاء للطباعة والنشرو التوزيع، [8] غريب سيد احمدو اخرون. دراسات في علم الاجتماع العائلي. الاسكندرية : دار المعرفة الجامعية، داءعة 1995. [9] مجمع اللغة العربية بالقاهرة ـ المعجم الوسيط .القاهرة : دار الدعوة للنشر ، 2010 ـ [10] محمد بن مكرم بن منظور . لسان العرب ـ بيروت : دار صادر للنشر،2010. [11] محمد منير مرسي ـ اصول التربية . القاهرة : عالم الكتب، 1997. [12] مصطفى بوتفنوشت ـ الأسرة .الجز ائر : شركة النشر الجزائرية ، 1980.

[13] وليم و لامبرتوو لاسأ.لامبرت ترجمة د.سلوى الملا.علم النفس الاجتماعي.القاهرة:دار الثروق للنشر و التوزيع،ط ث ، 1993.

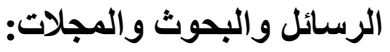
[1] ايمان بحي ونور الهدى مقدود. التكامل الوظيفي بين الأسرة والمدرسة وثأثيره على التحصيل الدراسي للتلميذ .الجزائر: رسالة ماجستير ، كلية العلوم الاجتماعية والانسانية ، جامعة الوادي، 2014.

[2] زعيمية منى .الأسرة المدرسة ومسار ات التعلم.الجز ائر : رسالة ماجستير ،جامعة منتوري -قسنطينة، 2013. [3] عمرونيتارزوليت حورية واخرون ـ واقع المساندة الاسرية لبعض المدارس الابتدائية في ولاية الوادي .الجزائر : جامعة قاصدي ، المونمر العلمي الثاني، 2013.

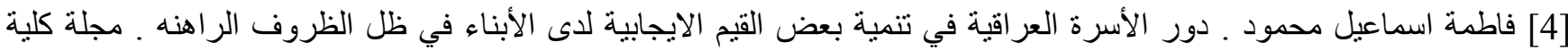
الاداب جامعة ديإلى ،2010 مجلد 3 العدد 106.

[5] فائزشلدان واخرون ، و اقع التواصل بين المدرسة الثانوية والمجتمع المحلي في محافظات غزة وسبل تحسينها. بحث مقدم إلى

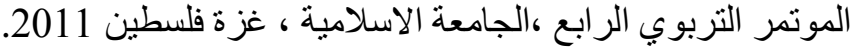

[6] فهد بن سلطان السلطان ـ و اقع التعاون بين المدرسة والمجتمع المحلي بمدينة الرياض باض بالمملكة العربية السعودية واهم الالاليات الللازمة لتطوبره ـ بحث منشور برسالة التربية و علم النفس جامعة الملك سعود ، الرياض السعودية السية 2008. [7] مر ابط احلام وشيماء مبارك ـ التكامل الوظيفي بين الأسرة و الكثافة الاسلامية في بناء الهوية الوطنية للمنخرطين. مجلة العلوم الانسانية و الاجتماعية جامعة قاصدي مرياح ورقلة، الجزائر 2011.

[8] مر اد زعيمي ـ مؤسسات التنشئة الاجتماعية . منشوار ات جامعة باجي مختار ، الجزائر 2006.

[9] موسى المطارنة ـ رفع مستوى الدافعية للطلبة نحو الدراسة ادوات واساليب، ورقة بحثية ـ الكلية العلمية الاسلامية ، الاردن ، .2013

[10] نبيل حميدشة ـ بعض الظروف المؤثرة على التحصيل الدراسي للتلميذ و اداء المعلم ـ رسالة ماجستير في علم الاجتماع، جامعة قسنطينة ، 1996.

[11] نجاة يحياوي ، مشاركة الأسرة للمدرسة وتكامل العلاقة بينهما ، بحث منشور ، جامعة بسكرة ، الجزائر 2010.

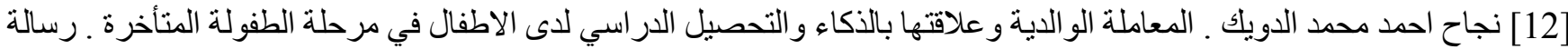
ماجستير ، كلية التربية علم النفس الجامعة الاسلامية، فلسطين غزة .2008 